Journal of Engineering and Applied Sciences 15 (2): 516-522, 2020

ISSN: 1816-949X

(C) Medwell Journals, 2020

\title{
Estimating Perceptions on the Public Sector's Contribution to Economic Development in South Africa
}

\author{
${ }^{1}$ Joel Lehlaba Thabane, ${ }^{2}$ Lebogang Eunice Sesale, ${ }^{2}$ Tshepo Ramarumo and \\ ${ }^{2}$ Solly Matshonisa Seeletse \\ ${ }^{1}$ Department of Mathematics and Applied Mathematics, \\ ${ }^{2}$ Department of Statistics and Operations Research, Sefako Makgatho Health Sciences University, \\ PO Box 107, 0204 MEDUNSA, Gauteng Province, South Africa
}

\begin{abstract}
Service delivery in the South African public sector seems to have eluded both the anticipated beneficiaries and the custodians who are the officials involved, role players and some stakeholders. The problem of the study was to investigate the role of the South Africa's public sector in economic development for the country. Twenty-eight managers in government departments shared their experiences in this study by providing information about the way their employees who should be prime to the responsibilities are familiar with the various aspects of public sectors in implementing out the mandate of development to improve the economy of South Africa. The managers found most employees to be inadequate for their jobs. In addition, they did not have impressions of confidence regarding their employees. The study recommended that proper merit-driven recruitment should be effected in the public sector and that public servants in the service be educated.
\end{abstract}

Key words: Corrective action, economic contribution, government, managers, information, public

\section{INTRODUCTION}

The public depend on their governments to provide rules and frameworks of contributing to and benefiting from the economy. In countries such as South Africa, service delivery such as electricity distribution, marine transportation, household sanitation, vehicle distribution and other major services are monopolized by the government and therefore, making service delivery a responsibility of government. With the insistence to be in charge of key economic sectors, the citizens expect government to be the largest contributor of the economy to the country. They expect their government to work and then deploys public servants who are astute to the tasks required. These are officials who are skilled with the necessary skills, knowledge and experiences to link communities with government using the services they provide to humanity. The case of South Africa and many other corrupt countries seems to be contrary (Reddy et al., 2005; Sibanda, 2012). In many of these countries, some of the political leaders disregard merit as they build their empire and the officials they appoint to positions also become corrupt because they do not know their mandate.

Anecdotal input from disgruntled members of the public in the rural areas (i.e., villages) and townships, personal observation and peer discussion seem to view current political leaders as focusing on political power to loot the countries wealth instead of seeking to uplift human lives. As a result, many of the public sector employees do not have knowledge about the role of the public sector and the services they should offer in order to enhance economic growth. Many employees in public offices do not even know that their workplaces have any bearing on economic development.

Quantitative measurement: Quantitative measurement is an essential approach in appraising enterprise status in which monitoring, evaluation and control for corrective action can be done (Patel, 2005; Revez and Borges, 2018). Quantitative methods are diverse and cover a wide range of applications. Apart from quantitative methods that were the original focus of statistics, there are many approaches which were designed to address questions of a qualitative nature. This study applies these methods. The analyses cover descriptive and inferential statistics. On the former, these are several common measures as well as several graphs and some tables. Chi-square tests are also applied to determine some incidence's independence on some traits visible in the employee's behaviours.

Corresponding Author: SM Seeletse, Department of Statistics and Operations Research, 


\section{MATERIALS AND METHODS}

The study was planned and conducted over a lengthy period from July, 2015 to December, 2018. The researchers involved in the study participated at different time epochs because of common interest and roping some in because of their experiences and the researches they had undertaken and completed earlier. The study requires both text and numbers to achieve its purpose. As a result, the mixed methodology research technique was used in addressing issues of relevance to the study purpose. The study covered numerous government departments in Gauteng, Limpopo and North-West provinces of South Africa. These areas were selected for the study because of their close proximity to the researcher's workplace and also due to the observation of the perceived lax attitude to the officials in the departments that were involved. The names of these departments cannot be disclosed due to the ethical guidelines that apply to this study.

Sampling: The South African government departments in the three provinces which were involved/used in this study, assisted in the use of purposive sampling because their members were knowledgeable in the issues of relevance to this study. Some heads of departments in the chosen departments were asked to inform on various issues of the study. Purposive sampling was therefore, chosen because the heads of departments (are supposed to) understand the roles of various role players and officials in their departments more than other employees as they are the ones appointing them.

Further, the heads of various departments understand government requirements and are the ones who receive reports from the officials/managers and memorandums from communities when they raise concerns about the department's performances. Purposive sampling was then applied because the heads of departments were the people who were most familiar with the aspects of the study (Kothari, 2008).

Data collection: The data collection instrument used in this research was a questionnaire. Structured and semi-structured open-and closed-ended questions were used in the questionnaire. The semi-structured open-ended questions enabled the respondents to explain without imposing restrictions on the participants regarding the issues of the study (Kothari, 2008). The questionnaire also allows feedback from either side which is often impractical when using other methods. It also allows the respondents the opportunity to provide anonymous feedback on their experiences. On the other hand, the closed-ended questions enabled measuring certain issues that the study needed in order to make calculations and estimations.
Data analysis: Qualitative text data from open-ended questions of the questionnaire was analysed using thematic content analysis. The quantitative data were processed using SPSS, the Statistical Package for Social Scientists. The analysis explored relationships between variables in order to determine the trends. Descriptive techniques used include measures of central tendencies, frequencies, graphs and percentages while inferential methods consisted of several chi-square statistical tests of independence.

\section{RESULTS AND DISCUSSION}

This study consists of a subsection discussing the study findings (or the results), followed by a discussion of the findings.

Years of experience: The following visual displays present the respondents demographic profiles. Most of the managers (contributing 13 occurrences) had experiences of 3 years, followed by those with experiences of 2 years occurring 12 times. Those with 4 year's experiences and higher as well as those with 1 year experience were fewer. The one with the highest experience has 7 years and none beyond this length of time (Table 1 and 2).

Level of education: The heads of departments who agreed to participate in the study were all having degree qualifications. The displays presented below demonstrate this fact (Table 3).

Table 1: Frequency table of years of experiences

\begin{tabular}{lcc}
\hline Years of experience & Frequencies & Percentages \\
\hline 1 & 6 & 15.0 \\
2 & 12 & 30.0 \\
3 & 13 & 32.5 \\
4 & 3 & 7.5 \\
5 & 4 & 10.0 \\
6 & 0 & 0.0 \\
7 & 2 & 5.0 \\
\hline
\end{tabular}

Table 2: Descriptive statistics

Years of experience

\begin{tabular}{ll} 
Variables & Values \\
\hline Mean & 2.825 \\
SE & 0.247779 \\
Median & 1.567089 \\
Mode & 2.455769 \\
Kurtosis & 1.119839 \\
Skewness & 0.810025 \\
Minimum & 1 \\
Maximum & 7 \\
\hline
\end{tabular}

Table 3: Frequency table of levels of education

\begin{tabular}{lcc}
\hline Level of education & Frequencies & Percentages \\
\hline Bachelor's degree & 21 & 75.0 \\
B Hons degree & 4 & 14.3 \\
Master's degree & 3 & 10.7 \\
Total & 28 & 100 \\
\hline
\end{tabular}


Table 4: Roles in the public sector

\begin{tabular}{lccccc}
\hline Items & SD & D & N & A & SA \\
\hline 1. & 6 & 25 & 6 & 3 & 1 \\
2. & 23 & 18 & 0 & 0 & 0 \\
3. & 21 & 18 & 1 & 0 & 1 \\
4. & 22 & 10 & 6 & 1 & 2 \\
5. & 14 & 15 & 8 & 2 & 1 \\
\multicolumn{5}{l}{ SA } \\
$=$
\end{tabular}

Most of the managers who participated, indicated to be having bachelor's degrees. They were more than five times those with Honours Bachelor degrees. The least were those with master's degrees who made only just below $13 \%$ of the number for the bachelor's degree. This indicates that although, they were holders of degree qualifications, fewer had higher degree qualifications. Also, none of them had a doctoral degree. The observation made is that the managers with lower qualifications than a Bachelor's degree did not participate in the study.

Roles in the public sector: The items are describes as follows (Table 4):

Item:

- Employees in my department understand the role of the public sector

- Employees know that the department has a role to play in developing the economy

- Employees in my department respect the roles of the public sector

- Employees work to ensure the department contributes to economic development

- Employees do not defraud the department

With the way the questions were asked, the positive skewness shape of the graph is an indication that most respondents were agreeing with the given statements.

Chi-square test of independence: The hypothesis being tested was whether the response given was independent of the item of the respondent's perception. In order to determine if it fits the proportions, a goodness-of-fit test using chi-square was appropriate (Wackerly et al., 2008). The null hypothesis that is being tested and the alternative hypothesis were given by:

$\mathrm{H}_{0}$ : Roles played in the public sector by the respondents and the responses are independent

$\mathrm{H}_{\mathrm{a}}$ : Roles played in the public sector and the responses are not independent

Let $\mathrm{o}_{\mathrm{i}}$ denote the ith observed frequencies and $\mathrm{e}_{\mathrm{i}}$ the corresponding expected frequencies in a contingency

\begin{tabular}{|c|c|c|c|c|}
\hline SA & $\mathrm{A}$ & $\mathrm{N}$ & $\mathrm{D}$ & SD \\
\hline \multicolumn{5}{|c|}{ Observed frequencies } \\
\hline 6 & 25 & 6 & 3 & 1 \\
\hline 23 & 18 & 0 & 0 & 0 \\
\hline 21 & 18 & 1 & 0 & 1 \\
\hline 22 & 10 & 6 & 1 & 2 \\
\hline 14 & 15 & 8 & 2 & 1 \\
\hline \multicolumn{5}{|c|}{ Expected frequencies } \\
\hline 17.2 & 17.2 & 4.2 & 1.2 & 1 \\
\hline 17.2 & 17.2 & 4.2 & 1.2 & 1 \\
\hline 17.2 & 17.2 & 4.2 & 1.2 & 1 \\
\hline 17.2 & 17.2 & 4.2 & 1.2 & 1 \\
\hline 17.2 & 17.2 & 4.2 & 1.2 & 1 \\
\hline$\chi^{2}=\sum_{i=}^{k}$ & $\left.\mathrm{e}_{\mathrm{i}} \mid-0.5\right)$ & & & \\
\hline 6.6564 & 3.0983 & 0.4024 & 1.4083 & 0.2500 \\
\hline 1.6331 & 0.0052 & 3.2595 & 0.4083 & 0.2500 \\
\hline 0.6331 & 0.0052 & 1.7357 & 0.4083 & 0.2500 \\
\hline 1.0750 & 2.6099 & 0.4024 & 0.0750 & 0.2500 \\
\hline 0.4238 & 0.1680 & 2.5929 & 0.0750 & 0.2500 \\
\hline
\end{tabular}

Table 5 (e.g., frequency table). The value of the test statistic (Bless et al., 2006) is given by the equation:

$$
\chi^{2}=\sum_{i=1}^{k} \frac{\left(o_{i}-e_{i}\right)^{2}}{e_{i}}
$$

When small observed frequencies $(<5)$, Simon (2002) recommends use of the Yates corrected chi-square equation which is given by:

$$
\chi^{2}=\sum_{i=1}^{\mathrm{k}} \frac{\left(\left|\mathrm{o}_{\mathrm{i}}-\mathrm{e}_{\mathrm{i}}\right|-0.5\right)^{2}}{\mathrm{e}_{\mathrm{i}}}
$$

In both versions the chi-square statistic's degrees of freedom (df) is given by $\mathrm{k}-1$ when the number of categories $\mathrm{k}$ is used (Curwin and Slater, 2002) or then by (c-1)(r-1) when the contingency table is a matrix having c columns and r rows (Tabachnick et al., 2007). Also, the rule is to reject the null hypothesis if the calculated test statistic exceeds the critical value obtained from Table 5 of chi-square statistics. The observed frequencies and the expected frequencies were presented together:

Since, some observed values are lower than 5, Eq. 2 is used to calculate the value of the test statistic. The value of the chi-square statistic is:

$$
\chi^{2}=\sum_{i=1}^{k} \frac{\left(\left|o_{i}-e_{i}\right|-0.5\right)^{2}}{e_{i}}=28.3260
$$

The $\mathrm{df}=(\mathrm{c}-1)(\mathrm{r}-1)=(5-1)$ and $(4)$ on $(5-1)(4)(4)=$ 16. At the $5 \%$ level of significance, the critical value is (Kutner et al., 2005). The test statistic exceeds the critical value, the null hypothesis cannot be rejected. There is no enough statistical evidence at the 5\% significance level that respondent's roles and their responses are independent. 
Leadership in the public sector: The items are described as follows (Table 6):

Item:

- Quality leadership is common in my department

- Employees in my department plan properly

- Employees in my department are well organised

- Employees deliver services properly to the people

- Employees discharge duties cost-effectively

\section{Chi-square test of independence:}

$\mathrm{H}_{0}$ : Respondent's responses and respondent's perceived leadership qualities are independent

$\mathrm{H}_{\mathrm{a}}$ : Respondent's responses and respondent's perceived leadership qualities are not independent

The value of the chi-square statistic is (Table 7):

$$
\chi^{2}=\sum_{i=1}^{k} \frac{\left(\left|o_{i}-e_{i}\right|-0.5\right)^{2}}{e_{i}}=15.4557
$$

The $\mathrm{df}=16$. Thus, the critical value at $5 \%$ level of significance is $\chi_{0.05}^{2}=26.2962$. The test statistic does not exceed the critical value. As a result, the hypothesis of independence cannot be rejected. This implies that there

\begin{tabular}{|c|c|c|c|c|c|}
\hline Item & SD & D & $\mathrm{N}$ & A & SA \\
\hline 1. & 25 & 14 & 0 & 2 & 0 \\
\hline 2. & 13 & 19 & 4 & 2 & 3 \\
\hline 3. & 23 & 10 & 5 & 2 & 1 \\
\hline 4. & 24 & 15 & 1 & 1 & 0 \\
\hline 5. & 18 & 20 & 1 & 1 & 1 \\
\hline
\end{tabular}

Table 7: Observed vs. expected responses

\begin{tabular}{|c|c|c|c|c|}
\hline SA & A & $\mathrm{N}$ & $\mathrm{D}$ & SD \\
\hline \multicolumn{5}{|c|}{ Observed frequencies } \\
\hline 25 & 14 & 0 & 2 & 0 \\
\hline 13 & 19 & 4 & 2 & 3 \\
\hline 23 & 10 & 5 & 2 & 1 \\
\hline 24 & 15 & 1 & 1 & 0 \\
\hline 18 & 20 & 1 & 1 & 1 \\
\hline \multicolumn{5}{|c|}{ Expected frequencies } \\
\hline 17.2 & 20.6 & 2.2 & 1.6 & 1 \\
\hline 17.2 & 20.6 & 2.2 & 1.6 & 1 \\
\hline 17.2 & 20.6 & 2.2 & 1.6 & 1 \\
\hline 17.2 & 20.6 & 2.2 & 1.6 & 1 \\
\hline 17.2 & 20.6 & 2.2 & 1.6 & 1 \\
\hline$\chi^{2}=\sum_{i=1}^{k}$ & $\mathrm{i}(-0.5)^{2}$ & & & \\
\hline 0.7383 & 0.0776 & 1.3136 & 0.0063 & 0.2500 \\
\hline 2.4471 & 0.5391 & 0.7682 & 0.0063 & 0.2500 \\
\hline 0.1752 & 1.6673 & 2.4045 & 0.0063 & 0.2500 \\
\hline 0.4083 & 0.0006 & 0.2227 & 0.0063 & 0.2500 \\
\hline 0.2141 & 0.975 & 0.2227 & 0.0063 & 0.2500 \\
\hline
\end{tabular}

is enough statistical evidence at the 5\% level of significance to believe that the respondent's responses and respondent's perceived leadership qualities are independent.

Economic opinionated view: The items are described as follows (Table 8):

- Employees understand that they have to save costs

- Employees assist people to emerge from poverty

- Employees deliver services to people free of corruption

- Employees work hard in the department

- Managers are biased towards hiring capable employees

\section{Chi-square test of independence:}

$\mathrm{H}_{0}$ : Respondent's economic preconceived notion of public section and perception items are independent

$\mathrm{H}_{\mathrm{a}}$ : Respondent's economic preconceived notion of public section and perception items are not independent

The value of the chi-square statistic is:

$$
\chi^{2}=\sum_{i=1}^{k} \frac{\left(\left|o_{i}-e_{i}\right|-0.5\right)^{2}}{e_{i}}=13.9222
$$

The $\mathrm{df}=16$. Therefore, the critical value at the $5 \%$ significance level is found to be about $\chi^{2}{ }_{0.05} 26.2962$. The test statistic does not exceed the critical value. Then the hypothesis of independence cannot be rejected.

The conclusion reached is therefore, that there is enough statistical evidence at the $5 \%$ significance level to believe that the respondent's economic preconceived notion of the public sector and the perception items are independent (Table 9).

Statistical comparison of accumulated items: This study combines the responses from each of the previous sections and then renames it with the central issue of the section. A graphical display is then drawn to show the comparison of these items. Thereafter the main issues and the responses are tested for independence. The items are

\begin{tabular}{|c|c|c|c|c|c|}
\hline Items & SD & $\mathrm{D}$ & $\mathrm{N}$ & A & $\mathrm{SA}$ \\
\hline 1. & 24 & 10 & 2 & 4 & 1 \\
\hline 2. & 15 & 21 & 2 & 2 & 1 \\
\hline 3. & 15 & 19 & 5 & 2 & 0 \\
\hline 4. & 15 & 19 & 5 & 1 & 1 \\
\hline 5. & 23 & 18 & 0 & 0 & 0 \\
\hline
\end{tabular}
described as follows: 
Table 9: Observed vs. expected responses

\begin{tabular}{|c|c|c|c|c|}
\hline SA & A & $\mathrm{N}$ & $\mathrm{D}$ & SD \\
\hline \multicolumn{5}{|c|}{ Observed frequencies } \\
\hline 24 & 10 & 2 & 4 & 1 \\
\hline 15 & 21 & 2 & 2 & 1 \\
\hline 15 & 19 & 5 & 2 & 1 \\
\hline 15 & 19 & 5 & 1 & 1 \\
\hline 23 & 18 & 0 & 0 & 1 \\
\hline \multicolumn{5}{|c|}{ Expected frequencies } \\
\hline 18.4 & 17.4 & 2.8 & 1.8 & 0.6 \\
\hline 18.4 & 17.4 & 2.8 & 1.8 & 0.6 \\
\hline 18.4 & 17.4 & 2.8 & 1.8 & 0.6 \\
\hline 18.4 & 17.4 & 2.8 & 1.8 & 0.6 \\
\hline 18.4 & 17.4 & 2.8 & 1.8 & 0.6 \\
\hline \multicolumn{5}{|c|}{$\chi^{2}=\sum^{\mathrm{k}} \underline{\left(\left|\mathrm{o}_{\mathrm{i}}-\mathrm{e}_{\mathrm{i}}\right|-0.5\right)^{2}}$} \\
\hline$\lambda_{i=1}$ & $e_{i}$ & & & \\
\hline 1.4136 & 2.7362 & 0.0321 & 1.6056 & 0.0167 \\
\hline 0.4571 & 0.5523 & 0.0321 & 0.0500 & 0.0167 \\
\hline 0.4571 & 0.0695 & 1.0321 & 0.0500 & 0.0167 \\
\hline 0.4571 & 0.0695 & 1.0321 & 0.0500 & 0.0167 \\
\hline 0.9136 & 0.0006 & 1.8893 & 0.9389 & 0.0167 \\
\hline
\end{tabular}

Table 10: Responses on accumulated public sector ideas

\begin{tabular}{lrrrrr}
\hline Items & SA & A & N & D & SD \\
\hline 1. & 86 & 86 & 21 & 6 & 5 \\
2. & 103 & 78 & 11 & 8 & 5 \\
3. & 92 & 87 & 14 & 9 & 3 \\
\hline
\end{tabular}

Item:

- Employees understand public sector roles

- They know leadership worth in the public sector

- They have economic preconceived notion

The skewness to the right is an indication that most respondents were agreeing with the given statements.

\section{Chi-square test of independence:}

$\mathrm{H}_{0}$ : Responses and the accumulated items are independent

$\mathrm{H}_{\mathrm{a}}$ : Responses and the accumulated items are not independent

The value of the chi-square statistic is:

$$
\chi^{2}=\sum_{i=1}^{k} \frac{\left(\left|o_{i}-e_{i}\right|-0.5\right)}{e_{i}}=5.0405
$$

The $\mathrm{df}=(\mathrm{c}-1)(\mathrm{r}-1)=(3-1)(5-1)=(2)(4)=8$. Therefore, the critical value at the $5 \%$ level of significance reads as $\chi_{0.05}{ }^{2}=15.5073$. The test statistic does not exceed the critical value. Then the hypothesis of independence cannot be rejected. This implies that there is enough statistical evidence at the 5\% significance level to believe that the responses on accumulated public sector ideas are independent (Table 10 and 11).

The discussion that follows, interprets the information presented in the statistical results such as the figures, tables and the tests of hypothesis.
Table 11: Observed vs. expected responses

\begin{tabular}{|c|c|c|c|c|}
\hline$\underline{\mathrm{SA}}$ & $\mathrm{A}$ & $\mathrm{N}$ & $\mathrm{D}$ & SD \\
\hline \multicolumn{5}{|c|}{ Observed frequencies } \\
\hline 86 & 86 & 21 & 6 & 5 \\
\hline 103 & 78 & 11 & 8 & 5 \\
\hline 92 & 87 & 14 & 9 & 5 \\
\hline \multicolumn{5}{|c|}{ Expected frequencies } \\
\hline 93.7 & 83.7 & 15.3 & 7.7 & 4.3 \\
\hline 93.7 & 83.7 & 15.3 & 7.7 & 4.3 \\
\hline 93.7 & 83.7 & 15.3 & 7.7 & 4.3 \\
\hline 93.7 & 83.7 & 15.3 & 7.7 & 4.3 \\
\hline 93.7 & 83.7 & 15.3 & 7.7 & 4.3 \\
\hline \multicolumn{5}{|c|}{$\chi^{2}=\sum_{i=1}^{k} \frac{\left(\left|o_{i}-e_{i}\right|-0.5\right)^{2}}{e_{i}}$} \\
\hline 0.5483 & 0.0402 & 1.7409 & 0.1775 & 0.0064 \\
\hline 0.8330 & 0.3191 & 0.9583 & 0.0036 & 0.0064 \\
\hline 0.0145 & 0.0959 & 0.0453 & 0.0906 & 0.1603 \\
\hline
\end{tabular}

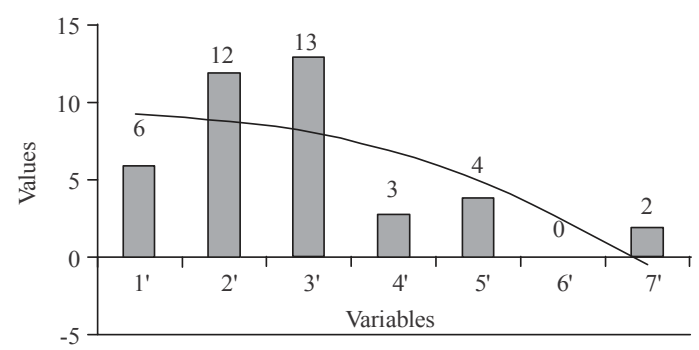

Fig. 1: Bar chart of years of experience $\left(y=-0.3929 x^{2}\right.$ $\left.+1.8929 \mathrm{x}+6, \mathrm{R}^{2}=0.4251\right)$

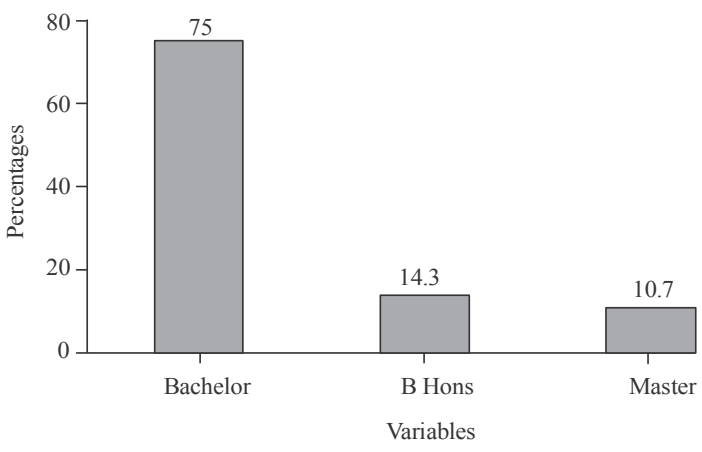

Fig. 2: Levels of education

Figures and Tables: Figure 1 and Table 1 express that most of the managers involved in the study had 2 years, followed by 3 years of experience. Others had 1 year while others had from 4 to 5 years, then 7 years of experience. None of these managers had 6 years of experience and no one exceeded 7 years of experience.

Figure 2 and Table 3 articulated that these managers had from bachelor's through to honours bachelor, up to master's degree qualifications. A majority of them showed to have possessed the lowest qualifications and the overall result showed to decrease in frequencies from low to high qualifications.

Figure 3 and Table 4 illustrated that most of the managers seem to have found: 


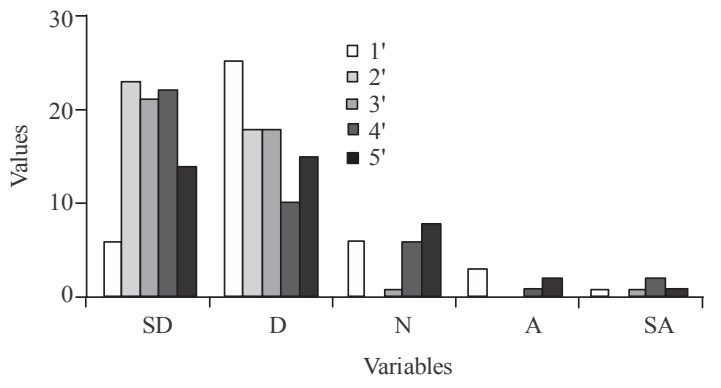

Fig. 3: Roles in the public sector

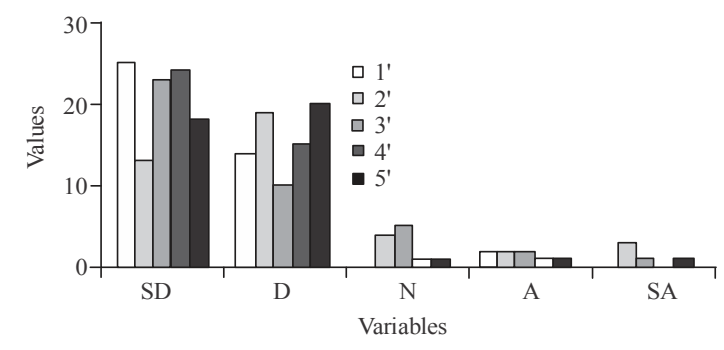

Fig. 4: Leadership in the public sector

- Their employees to be lacking an understanding of the public sector's role

- Most could not play a role to develop the economy

- Most did not respect the public sector's role

- Most did not work hard towards economic development and

- Most found their employees to have defrauded the department

Figure 4 and Table 6 also show that:

- Most managers did not experience their employee's merit

- Most found their departments to lack quality leadership

- Most found their employees to be failing in planning

- Most found their employees to be poorly organized

- Most stated that their employees did not deliver proper services and

- Most stated that their employees did not discharge duties cost-effectively

Figure 5 and Table 8 displayed that:

- Most managers found their employees to lack understanding of cost saving

- Most found the employees not assisting people to leave poverty

- Most found their employees to be corrupt

- Most found no hard work in their employees

- Most stated that recruitment is biased

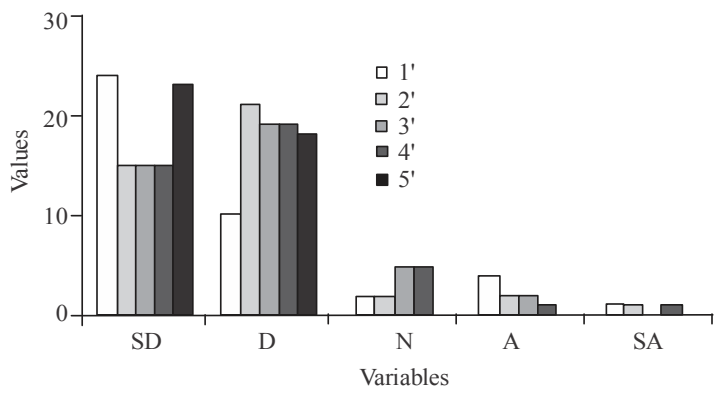

Fig. 5: Ecnomic opinionated view

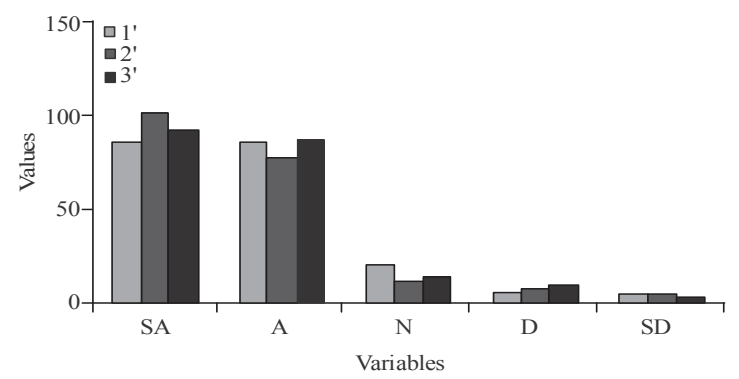

Fig. 6: Responses on accumulated public sector ideas

Figure 6 and Table 10 summed that most managers viewed their employees:

- To lack understanding of public sector role

- To lack knowledge of leadership value

- To have no understanding of their role worth towards the economy

Chi-square tests: The first chi-square test conducted in this study showed that the roles played by officials in the public sector and the responses are not independent. The roles were found to be mostly deficient. This is an indication that a significant proportion of managers could still be playing their roles to enhance economic development.

The ensuing chi-square test demonstrated that the responses and the perceived leadership qualities of the managers in the public sectors were independent traits. Since, leadership was also adjudged to be deficient, it is therefore concluded that this revelation can be thought to be realistic.

\section{CONCLUSION}

The study stretched from several years in order to obtain data from willing participants. The findings showed statistically that most of the managers who participated in the study, viewed the public sector as failing to contribute impartially and adequately to the South Africa's economic development. 


\section{ACKNOWLEDGEMENT}

The researcher acknowledges the support of colleagues in the Department of Statistics and Operations Research at the Sefako Makgatho Health Sciences University, South Africa for encouraging hard work on the project. Some of them even took responsibilities of those who were on the project to accomplish this study. The department supported this study with finances.

\section{REFERENCES}

Bless, C., C.H. Smith and A. Kagee, 2006. Fundamentals of Social Research Methods: An African Perspective. 3rd Edn., Juta and Company Ltd, South Africa,.

Curwin, J. and R. Slater, 2002. Quantitative Methods for Business Decision. 5th Edn., Thomson Learning, London, UK.

Kothari, C.R., 2008. Research Methodology: Methods and Techniques. New Age International (P) Limited, New Delhi, India, Pages: 418.

Kutner, M.H., C.J. Nachtsheim, J. Neter and W. Li, 2005. Applied Linear Statistical Models. 5th Edn., McGraw-Hill, Boston, Massachusetts, ISBN: 9780072386882 , Pages: 1396.
Patel, P., 2005. Introduction to Quantitative Methods. Harvard Law School, Cambridge, Massachusetts,.

Reddy, P.S., P. Naidoo and P. Pillay, 2005. Local democracy and developmental local government in South Africa beyond the first decade: Quo vadis?. Africanus, 35: 40-52.

Revez, J. and L.C. Borges, 2018. Pragmatic paradigm in information science research: A literature review. Qual. Quant. Methods Libraries, 7: 583-593.

Sibanda, M.M.M., 2012. Monitoring customer-focused quality service delivery in local government: Conceptual issues and perspectives for consideration. Afr. Public Serv. Delivery Perform. Rev., 1: 4-25.

Simon, M.K., 2002. Probability Distributions Involving Gaussian Random Variables. Springer, New York, USA., ISBN-13: 9781402070587.

Tabachnick, B.G., L.S. Fidell and J.B. Ullman, 2007. Using Multivariate Statistics. 5th Edn., Pearson, Boston, Massachusetts,.

Wackerly, D., W. Mendenhall and R.L. Scheaffer, 2008. Mathematical Statistics with Applications. Brooks-Cole Publishing, Belmont, California, USA., Page: 341 . 